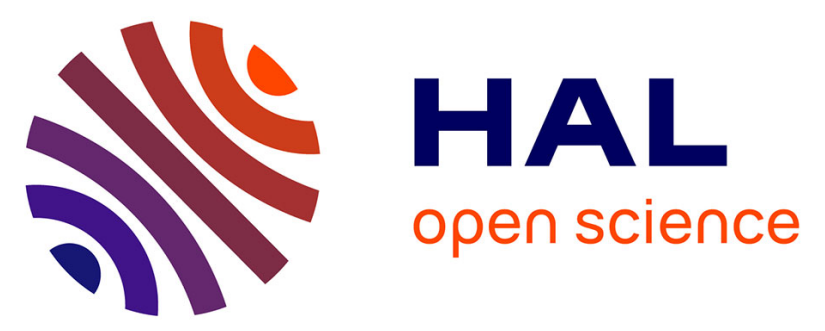

\title{
Effect of adding gefitinib to neoadjuvant chemotherapy in estrogen receptor negative early breast cancer in a randomized phase II trial
}

Mogens Bernsdorf, Christian Ingvar, Leif Jörgensen, Malgorzata K. Tuxen, Erik H. Jakobsen, Anna Saetersdal, Marie Louise Kimper-Karl, Niels Kroman, Eva Balslev, Bent Ejlertsen

\section{To cite this version:}

Mogens Bernsdorf, Christian Ingvar, Leif Jörgensen, Malgorzata K. Tuxen, Erik H. Jakobsen, et al.. Effect of adding gefitinib to neoadjuvant chemotherapy in estrogen receptor negative early breast cancer in a randomized phase II trial. Breast Cancer Research and Treatment, 2011, 126 (2), pp.463470. 10.1007/s10549-011-1352-2 . hal-00608808

\section{HAL Id: hal-00608808 https://hal.science/hal-00608808}

Submitted on 15 Jul 2011

HAL is a multi-disciplinary open access archive for the deposit and dissemination of scientific research documents, whether they are published or not. The documents may come from teaching and research institutions in France or abroad, or from public or private research centers.
L'archive ouverte pluridisciplinaire HAL, est destinée au dépôt et à la diffusion de documents scientifiques de niveau recherche, publiés ou non, émanant des établissements d'enseignement et de recherche français ou étrangers, des laboratoires publics ou privés. 


\section{Effect of adding gefitinib to neoadjuvant chemotherapy in estrogen}

\section{receptor negative early breast cancer in a randomized phase II trial.}

Mogens Bernsdorf ${ }^{1}$, Christian Ingvar ${ }^{2}$, Leif Jörgensen ${ }^{3}$, Malgorzata K. Tuxen ${ }^{4}$, Erik H. Jakobsen ${ }^{5}$, Anna

Saetersdal ${ }^{6}$, Marie Louise Kimper-Karl ${ }^{7}$, Niels Kroman ${ }^{8}$, Eva Balslev ${ }^{9}$, Bent Ejlertsen ${ }^{1}$

(1) Department of Oncology, Copenhagen University Hospital, Denmark. (2) Department of Surgery, Clinical Sciences, Lund University, Sweden. (3) AstraZeneca Sverige, Sweden. (4) Department of Oncology, Herlev Hospital, Denmark. (5) Department of Oncology, Lillebaelt Hospital, Vejle, Denmark. (6) Department of Oncology, Rikshospitalet-Radiumhospitalet - Medical Center, Oslo, Norway. (7) Department of Oncology, Odense University Hospital, Denmark. (8) Department of Breast Surgery, Copenhagen University Hospital, Denmark. (9) Department of Pathology, Herlev Hospital, Denmark.

\section{Acknowledgment}

The study was sponsered by Astra Zeneca. We would like to thank the following centers for provision of study material: Sweden: Malmö Hospital and Lund University Hospital. Norway: Trondheim Hospital and Rikshospitalet-Radiumhospitalet Oslo. Denmark: Herlev Hospital, Aarhus University Hospital, Odense University Hospital, Vejle Hospital, Roskilde Hospital, Naestved Hospital and Ringsted Hospital. Contribution of Charlotte Levin Tykjaer Jörgensen is gratefully acknowledged.

\section{Corresponding author:}

Mogens Bernsdorf

Department of Oncology,

Copenhagen University Hospital,

Blegdamsvej 9,

DK-2100 Copenhagen 0

Phone: + 4535459693

Fax: + 4535454391

Email: mogenspetersen@gmail.com 


\section{$\underline{\text { Introduction }}$}

The long term outcome of NAC has been investigated in large randomized trials, which neither have been able to detect a difference in disease free survial (DFS) or overall survival (OS), when compared to adjuvant chemotherapy [1-4].

Systemic NAC may result in local tumor regression or even pathologic complete response $(\mathrm{pCR})$. The complete eradication of detectable tumor is a prognostic marker, associated with improved outcome [2;5-7]. Tumors with absence of estrogen (ER) and progesterone $(\mathrm{PgR})$ receptors have higher response rates to NAC and are more likely to achieve a pCR [5;6;8;9]. Epidermal growth factor receptor (EGFR) is a transmembrane receptor with tyrosine kinase activity, which stimulates a series of intracellular pathways responsible for cell proliferation, downregulating apoptosis, invasion, metastasis and angiogenesis [10;11]. Although studies have demonstrated an inverse relationship between the expression of ER and EGFR [2-14], and suggested a connection between EGFR and the basal-like phenotype [12;15;16], the function and clinical significance of EGFR in breast cancer are still poorly understood. Preclinical in vivo $[7 ; 17]$ and in vitro $[7 ; 13]$ studies have shown that gefitinib (Iressa ${ }^{\circledR}$, Astra Zeneca), a selective EGFR tyrosine kinase inhibitor, exhibits anti-proliferative and anti-tumor activity in breast cancer. Although anti-EGFR agents, like gefitinib, excert their effect through the EGF receptor, a connection between EGFR expression and the clinical activity of the EGFR directed drugs has not clearly been demonstrated $[11 ; 17 ; 18]$. Amplifications and mutations of EGFR are rarely seen in breast cancer $[11 ; 12 ; 19 ; 20]$ thus limiting their clinical utility as predictive markers. Furthermore it is hypothesized that gefitinib can both potentiate the effect $[7 ; 17]$ and cause a reversal of resistance to anthracyclines [21]. 
Triple-negative breast cancer (TNBC) is characterized by the lack of expression of ER, $\mathrm{PgR}$ and human epidermal growth factor receptor 2 (HER2) and has been associated with an increased $\mathrm{pCR}$ rate compared to non-TNBC [22].

NAC containing anthracycline has by far been the most extensively studied cytotoxic combination and the combination of epirubicin and cyclophosphamide (EC) for a duration of 4-6 cycles is an effective regimen and remains a standard in neoadjuvant treatment of breast cancer patients [2;23;24]. The anthracyclines, epirubicin and doxorubicin, have similar cytotoxic effect and have been combined with and compared to other cytotoxic drugs, with no combination clearly being superior to the other [23;24]. With the introduction of molecular targeted drugs into cancer treatment, there are a great number of agents for evaluation in combination with anthracycline and taxane based therapy, with the objective of increasing the $\mathrm{pCR}$ rate.

This randomized phase II trial (NCT 00239343) was designed to compare pCR after four cycles of EC plus gefitinib to four cycles of EC plus placebo in patients with ER negative breast cancer.

\section{Patients and Methods}

\section{Study Design}

NICE was a Nordic phase II, multicenter, two-armed double-blind randomized trial involving 12 centers in Denmark, Norway and Sweden examining the effect of adding gefitinib to EC. In addition, a correlative science study was conducted including blood samples and tumor biopsies taken before and after four cycles of EC and gefitinib or placebo. Results from the correlative science studies will be reported elsewhere. 
Ethical committees approved the study protocol and the study was conducted according to the Helsinki declaration. All study participants provided written informed consent. This trial is registered on the ClinicalTrials.gov website, NCT 00239343.

\section{Patients}

Eligible patients were women with unilateral, primary operable, ER negative invasive breast cancer $\geq 2 \mathrm{~cm}$. Exclusion criteria included inflammatory breast cancer, involvement of skin or muscle, involvement of supraclavicular lymph nodes or evidence of distant metastases, a history of unstable or uncompensated respiratory, cardiac, hepatic or renal disease.

Patients were randomized sequentially in a 1:1 ratio when eligibility had been established.

\section{$\underline{\text { Treatment }}$}

Patients were randomly assigned to either four cycles of EC (epirubicin $90 \mathrm{mg} / \mathrm{m}^{2}$ and cyclophosphamide $600 \mathrm{mg} / \mathrm{m}^{2}$ ) plus 12 weeks of daily treatment with gefitinib $250 \mathrm{mg}$ or EC plus 12 weeks treatment with placebo. Chemotherapy was administered every 3 weeks.

Gefitinib and placebo tablets were of identical appearance and package and no personnel with direct connecion to the study had acces to randomization code or unblinded data until database had been unlocked.

Treatment with chemotherapy was postponed, if blood counts on day 1 showed leukocytes below $2.5 \times 10^{9} / \mathrm{l}$ or platelets below $50 \times 10^{9} / \mathrm{l}$, until these values were again reached. Unless reached within two weeks or following febrile neutropenia grade 4 or leucopenia grade 4 , epirubicin was reduced by $15 \mathrm{mg} / \mathrm{m}^{2}$ and cyclophosphamide by $100 \mathrm{mg} / \mathrm{m}^{2}$ in 
subsequent courses. Other toxicities related to epirubicin and/or cyclophosphamide was handled at the investigators discretion.

Dose interruptions for up to maximum 14 days were the first approach to managing toxicity related to gefitinib. Dose reduction for gefitinib was not allowed.

After four cycles of EC and placebo or gefitinib, patients underwent mastectomy or breast conserving surgery, including surgical removal of residual tumor and surrounding tissue. Postoperatively, patients received additional chemotherapy, trastuzumab and radiotherapy, according to local guidelines.

\section{Assessments}

Upon study entry and prior to surgery, tumor assessment consisting of breast palpation, mammography and breast ultrasonography was performed. In case of disagreement regarding tumor size, the ultrasonography prevailed. Blood samples and core biopsies were taken before initiation of trial medication. Breast palpation was also performed before each series of chemotherapy. A medical history including assessment of adverse events $(\mathrm{AE})$ and a clinical examination were recorded at each 3-week visit.

\section{Endpoints}

The primary endpoint was pCR defined as no evidence of invasive cancer in the breast. A central review of pathologic tumor response in all patients, was conducted on tumor sections or blocks by one independent pathologist (EB) at Department of Pathology, Herlev Hospital, Copenhagen. The independent pathologist's decision on pathologic response was used as final assessment.

Secondary endpoints were complete $(\mathrm{CR})$ and overall objective tumor $(\mathrm{OR})$ response as assessed by the response evaluation criteria in solid tumors (RECIST) criteria. CR was 
defined as complete disappearance of tumor. A tumor regression of $>30 \%$ was defined as a partial response (PR) whereas tumor progression $>20 \%$ was considered progression of disease (PD). A tumor that neither fulfilled the criterion for PR or PD was considered stable disease (SD).

All secondary endpoints was reported by the investigators.

The severities of AEs were graded according to the National Cancer Institute Common Toxicity Criteria (NCI CTC vs. 2.0).

\section{Immunohistochemistry and Flouroscence In Situ Hybridization}

ER and PgR immunostaining was carried out according to local guidelines prior to inclusion, and classified as negative if less than $10 \%$ of cells were stained. Frozen and formalin fixed paraffin-embedded (FFPE) tumor tissue was collected at baseline and at the time of definitive surgery.

All FISH analyses were performed at the Department of Pathology, Herlev Hospital, Copenhagen. HER2 copy number was visualized by FISH (HER2 pharm Dx ${ }^{\mathrm{TM}}$, Dako, Glostrup, Denmark) according to the manufacturer's instructions. Tumors were scored as HER2 positive or amplified when the gene to centromere 17 ratio was $\geq 2$.

\section{Statistical analysis}

This trial was designed to demonstrate that the addition of gefitinib to an EC regime would increase the $\mathrm{pCR}$ rate. We estimated that 77 patients per arm would be needed in order for the study to have a $90 \%$ power to detect a standardized difference of 0.526 at a 2 sided $5 \%$ significance level in a given parameter. 
All patients that were enrolled, randomized and received study treatment were considered the intention to treat population (ITT). The analysis population for all efficacy endpoints was the per protocol population (PP) and for the safety endpoints the ITT population was used for analysis. The PP consisted of those subjects from the ITT population that were not major protocol deviators, and subjects included in the PP were to be fully evaluable; adequate tumor sample for histological analysis at baseline and at surgery. Patients who completed treatment but had poor compliance, defined as number of missed doses exceeding $20 \%$ and/or less than 10 consecutive days of treatment immediately prior to surgery at 12 weeks, were considered major protocol deviators and excluded from the PP. Prior to unblinding, protocol deviators, major and minor, were identified to ascertain the PP population.

The primary and secondary variables were analysed by a Chi-square test to find the percentage of patients responding in the two groups and a $p$-value for the difference. The Fisher's exact test was used in subgroup analysis, to evaluate differences in pCR between triple negative and non-triple negative tumors.

\section{$\underline{\text { Results }}$}

A total of 181 patients were randomized from October 2004 to May 2007 into this study (figure 1). One patient randomized to the placebo group discontinued the study before receiving any treatment, leaving 180 patients in the ITT population; comprising 94 patients assigned to the gefitinib group and 86 assigned to the placebo group. Baseline characteristics were well balanced in the two groups, but HER2 amplification was more common in the placebo (37.2\%) than in the gefitinib (23.4\%) group (table 1$)$. 
In all 158 patients completed treatment, while the remaining $23(12.7 \%)$ patients discontinued treatment due to adverse events (AE) (11 patients), progression of disease (3 patients), non-eligible (5 patients) and other reasons (4 patients). Another 14 patients, who completed treatment, were retrospectively identified as major protocol deviators and excluded from the PP leaving 144 subjects in the PP, comprising 71 patients in the gefitinib group and 73 in the placebo group. Major protocol deviations leading to exclusions included primary tumor under $2.0 \mathrm{~cm}$ (8 patients), primary tumor being ER positive (5 patients) and safety reasons (12 patients) (table 2). Patients with primary tumor being either $<2.0 \mathrm{~cm}$ or ER postive were erroneously included.

\section{Tumor parameters}

The mean tumor size, measured by palpation, mammography and ultrasonography, was comparable between the two treatment groups, with ultrasonography showing a mean diameter of $3.0 \mathrm{~cm}$ (range $2-8 \mathrm{~cm}$ ) in gefitinib treated patients and $3.3 \mathrm{~cm}$ (range $2-12 \mathrm{~cm}$ ) in the placebo group. Table 4 summarizes baseline target tumor evaluation (RECIST criteria) for the PP.

\section{Tumor Response}

All tumor response data has been reviewed centrally, showing only minor deviations compared to investigators' data. All tumor response data presented are investigators. No significant differences in response across the evaluation parameters were recorded at the time of surgery between the treatment groups. Table 5 summarizes pathologic and clinical tumor responses in the PP population.

Pathologic complete response was observed in $17 \%$ of patients treated with gefitinib (12/71) and in $12 \%$ of patients treated with placebo (9/73) with a difference of $4.57 \%$ (95\% 
$\mathrm{Cl},-7.19-16.33 ; \mathrm{p}=0.44)$. There was no difference in $\mathrm{CR}$ as this was observed in $10 \%$ of patients in both the gefitinib (7/71) and placebo group (7/73) with a difference of $0.27 \%$ (95\% CI, -9.61 -10.2; $p=0.96)$. The ITT population showed similar results $(p=0.86)$. A non-significant difference in OR $(5.96 \% ; 95 \% \mathrm{Cl},-9.94-21.86 ; \mathrm{p}=0.45)$ was observed between the two groups, with a tumor response observed in $68 \%(48 / 71)$ of patients treated with gefitinib, 62\% (45/73) in the placebo group and 65\% (93/144) combined. At the time of surgery a PD was observed in two patients in the placebo group (2/73, $2.7 \%)$ and in $5(7.0 \%, p=0.23)$ patients treated with gefitinib.

Post-hoc subgroup analysis showed a significant difference $(p=0.03)$ in pCR between TNBC and tumors that were either HER2 and/or PgR positive independent of treatment. 12 of 82 TNBC (gefitinib: 7/41, placebo: 5/41) achieved a pCR (15\%) compared to 1 of 48 that were non-TNBC (2\%). TNBC-status could be established on 130/144 tumors. A pCR was seen in 8 of the 14 tumors, where TNBC-status could not be established.

\section{Toxicity}

The addition of gefitinib was associated with a higher incidence of AEs and the most frequently reported in both groups were nausea, alopecia and fatigue. The incidence of diarrhoea and rash/acne/dermatitis were more frequent in the gefitinib group (49, 52\%), than in the placebo group $(17,20 \%)$, and were the most common reported AEs leading to discontinuation and they were reported only in the gefitinib group. More patients from the gefitinib group (9/94) discontinued treatment, than in the placebo group (2/86), due to AEs. The patients in the gefitinib group suffered more serious adverse events (SAE) than patients in the placebo group. Febrile neutropenia was observed in 17 out of 94 patients $(18.1 \%)$ in the gefitinib group and in 8 out of 87 patients $(9.2 \%)$ from the placebo group. 
No deaths were reported. The most frequent SAE's and their distribution across the treatment groups are listed in table 3.

\section{Discussion}

The addition of gefitinib to EC in a neoadjuvant setting was expected to increase the rate of $\mathrm{pCR}$. This expectation, was based on preclinical studies showing that gefitinib had both anti-proliferative and anti-tumor activity, as well as indicating a synergy between gefitinib and anthracycline [7;13;17]. Our results demonstrate, that the EGFR inhibitor gefitinib does not increase $\mathrm{pCR}$ rate in a neoadjuvant setting among ER negative breast cancer patients.

Furthermore, the addition of gefitinib to an EC regimen did not result in an increase of CR or OR rates, therefore not supporting a possible synergy between gefitinib and anthracycline.

The addition of gefitinib to EC resulted in an increase in toxicity, and discontinuations of treatment due to AEs were more frequent in the gefitinib group (9/94) than in the placebo group (2/84). More importantly, the incidence of SAE's was higher in the gefitinib group, due to more episodes of febrile neutropenia. Other studies, that have reported on adverse events with gefitinib, have not observed a higher incidence in hematologic toxicities in the gefitinib arm, but otherwise reported similar adverse events [10;25].

With no other antineoplastic treatment than the study drug, administered before or during the study, the results are without influence from other therapeutics, and therefore resemble the direct effect of EC with and without gefitinib on both primary and secondary endpoints. This trial had a biological hypothesis and the outcome is a strong indicator for no further evaluation of gefitinib in this setting. Amplification of $H E R 2$ has been associated with sensitivity to anthracycline [26;27] and a higher proportion of HER2 amplified tumors in the 
placebo group, could indicate a randomization problem and have concealed an effect of gefitinib. The latter though, seems unlikely since only 2 patients, in both the geftinib group (17\%) and the placebo group (22\%), that obtained a pCR were HER2 amplified.

Molecular profiling methods have been used to identify clinically relevant subtypes and propose a new classification of breast cancer. The subtypes are defined by their genetic expression profiles and include: normal breast-like, luminal-like A, luminal-like B, HER2 positive and basal-like subtypes. Studies have suggested a connection between the basallike subgroup and overexpression of EGFR [15]. Although, no connection between EGFR expression and response to anti-EGFR therapy $[10 ; 11 ; 17]$ has been demonstrated, choosing a different subgroup of patients, other than ER negative, might have been more appropriate, but remains unclear and needs further scientific investigation. As of now, there is no clear way to select patients that would benefit from anti-EGFR treatment in breast cancer [12]. However, post-hoc subgroup analysis of our data showed that TNBC were more likely to achieve a pCR than non-TNBC, which is in line with a previously published study [22]. Additional biomarker studies, which might add information on how to select appropriate patients, are in the progress.

The results of our study are similar to other neoadjuvant studies with regards to both clinical response and $\mathrm{pCR}$. Others have previously reported similar $\mathrm{pCR}$ rates between ER positive and ER negative tumors in a prospective neoadjuvant trial [28], but a higher OR in an ER negative based patient group was expected, since several studies $[5 ; 6 ; 8 ; 9]$, in subgroup analysis, have showed that ER negative tumors are more sensitive to chemotherapy than ER positive tumors. We did not observe an improved combined OR in our trial, as a OR of $65 \%$ is in accordance with studies $[5 ; 6 ; 8 ; 9]$ that included patients with mixed ER status. 
Whether or not, as indicated by others [12-14], an inverse relationship between EGFR and ER expression exists, awaits conduction of further gene expression analysis. If such an inverse relationship exists, the mechanism of action of gefitinib may be, as anticipated by others $[10 ; 11 ; 17 ; 18]$, more than simple inhibition of the EGFR tyrosine kinase.

A combination regimen, consisting of anthracycline and taxane-based chemotherapy is now the treatment of choice for neoadjuvant treatment of breast cancer, since both the NSABP-B27 and the Gerparduo trials showed increased pCR rates with the addition of a taxane $[6 ; 9]$. Whether this increase in $\mathrm{pCR}$ will improve long-term patient outcome is still unknown. In our study, patients were given postoperative chemotherapy by investigators choice.

Molecular targeted treatment provides opportunities for these agents to be added to chemotherapeutic regimens, but still requires assessment and monitoring of molecular, pathologic and genetic markers that may or may not predict response to a specific regimen. So far, anti-HER2 treatment is the only molecular targeted drug that has demonstrated effect in randomized neoadjuvant breast cancer trials [28] and since a clinical benefit of treatment with EGFR inhibitors in breast cancer patients has not been established, there is a need for identification and clinical validation of useful criteria for selecting patients that potentially could benefit from such treatment.

\section{Acknowledgment}

The study was sponsered by Astra Zeneca. We would like to thank the following centers for provision of study material: Sweden: Malmö Hospital and Lund University Hospital. Norway: Trondheim Hospital and Rikshospitalet-Radiumhospitalet Oslo. Denmark: Herlev Hospital, Aarhus University Hospital, Odense University Hospital, Vejle Hospital, Roskilde Hospital, Naestved Hospital and Ringsted Hospital. Contribution of Charlotte Levin Tykjaer Jörgensen is gratefully acknowledged. 


\section{Reference List}

(1) Rastogi P, Anderson SJ, Bear HD, Geyer CE, Kahlenberg MS, Robidoux A, et al (2008) Preoperative chemotherapy: updates of National Surgical Adjuvant Breast and Bowel Project Protocols B-18 and B-27. J Clin Oncol 26:778-85.

(2) Kaufmann M, von MG, Bear HD, Buzdar A, McGale P, Bonnefoi H, et al (2007) Recommendations from an international expert panel on the use of neoadjuvant (primary) systemic treatment of operable breast cancer: new perspectives 2006. Ann Oncol 18:1927-34.

(3) Mauri D, Pavlidis N, Ioannidis JP (2005) Neoadjuvant versus adjuvant systemic treatment in breast cancer: a meta-analysis. J Natl Cancer Inst 97:188-94.

(4) Mieog JS, van der Hage JA, van d, V (2007) Preoperative chemotherapy for women with operable breast cancer. Cochrane Database Syst Rev CD005002.

(5) Dieras V, Fumoleau P, Romieu G, Tubiana-Hulin M, Namer M, Mauriac L, et al (2004) Randomized parallel study of doxorubicin plus paclitaxel and doxorubicin plus cyclophosphamide as neoadjuvant treatment of patients with breast cancer. J Clin Oncol 22:4958-65.

(6) Bear HD, Anderson S, Smith RE, Geyer CE, Jr., Mamounas EP, Fisher B, et al (2006) Sequential preoperative or postoperative docetaxel added to preoperative doxorubicin plus cyclophosphamide for operable breast cancer: National Surgical Adjuvant Breast and Bowel Project Protocol B-27. J Clin Oncol 24:2019-27.

(7) Ciardiello F, Caputo R, Bianco R, Damiano V, Pomatico G, De PS, et al (2000) Antitumor effect and potentiation of cytotoxic drugs activity in human cancer cells by ZD-1839 (Iressa), an epidermal growth factor receptor-selective tyrosine kinase inhibitor. Clin Cancer Res 6:2053-63.

(8) Colleoni M, Viale G, Zahrieh D, Pruneri G, Gentilini O, Veronesi P, et al (2004) Chemotherapy is more effective in patients with breast cancer not expressing steroid hormone receptors: a study of preoperative treatment. Clin Cancer Res 10:6622-8.

(9) von MG, Raab G, Caputo A, Schutte M, Hilfrich J, Blohmer JU, et al (2005) Doxorubicin with cyclophosphamide followed by docetaxel every 21 days compared with doxorubicin and docetaxel every 14 days as preoperative treatment in operable breast cancer: the GEPARDUO study of the German Breast Group. J Clin Oncol 23:2676-85.

(10) Mendelsohn J, Baselga J (2003) Status of epidermal growth factor receptor antagonists in the biology and treatment of cancer. J Clin Oncol 21:2787-99.

(11) Ciardiello F, Tortora G (2008) EGFR antagonists in cancer treatment. N Engl J Med Mar 358:1160-74.

(12) Faratian D, Bartlett J (2008) Predictive markers in breast cancer--the future. Histopathology 52:91-8.

(13) McClelland RA, Barrow D, Madden TA, Dutkowski CM, Pamment J, Knowlden JM, et al (2001) Enhanced epidermal growth factor receptor signaling in MCF7 breast cancer cells after long-term culture in the presence of the pure antiestrogen ICI 182,780

(Faslodex). Endocrinology 142:2776-88. 
(14) Sainsbury JR, Farndon JR, Sherbet GV, Harris AL (1985) Epidermal-growth-factor receptors and oestrogen receptors in human breast cancer. Lancet 1:364-6.

(15) Nielsen TO, Hsu FD, Jensen K, Cheang M, Karaca G, Hu Z, et al (2004) Immunohistochemical and clinical characterization of the basal-like subtype of invasive breast carcinoma. Clin Cancer Res 10:5367-74.

(16) Hoadley KA, Weigman VJ, Fan C, Sawyer LR, He X, Troester MA, et al (2007) EGFR associated expression profiles vary with breast tumor subtype. BMC Genomics 8:258.

(17) Sirotnak FM, Zakowski MF, Miller VA, Scher HI, Kris MG (2000) Efficacy of cytotoxic agents against human tumor xenografts is markedly enhanced by coadministration of ZD1839 (Iressa), an inhibitor of EGFR tyrosine kinase. Clin Cancer Res 6:4885-92.

(18) Baselga J, Albanell J, Ruiz A, Lluch A, Gascon P, Guillem V, et al (2005) Phase II and tumor pharmacodynamic study of gefitinib in patients with advanced breast cancer. J Clin Oncol 23:5323-33.

(19) Milanezi F, Carvalho S, Schmitt FC (2008) EGFR/HER2 in breast cancer: a biological approach for molecular diagnosis and therapy. Expert Rev Mol Diagn 8:417-34.

(20) Lynch TJ, Bell DW, Sordella R, Gurubhagavatula S, Okimoto RA, Brannigan BW, et al (2004) Activating mutations in the epidermal growth factor receptor underlying responsiveness of non-small-cell lung cancer to gefitinib. N Engl J Med 350:2129-39.

(21) Yang $\mathrm{CH}$, Huang CJ, Yang CS, Chu YC, Cheng AL, Whang-Peng J, et al (2005) Gefitinib reverses chemotherapy resistance in gefitinib-insensitive multidrug resistant cancer cells expressing ATP-binding cassette family protein. Cancer Res 65:6943-9.

(22) Liedtke C, Mazouni C, Hess KR, Andre F, Tordai A, Mejia JA, et al (2008) Response to neoadjuvant therapy and long-term survival in patients with triple-negative breast cancer. J Clin Oncol 26:1275-81.

(23) Sachelarie I, Grossbard ML, Chadha M, Feldman S, Ghesani M, Blum RH (2006) Primary systemic therapy of breast cancer. Oncologist 11:574-89.

(24) Buzdar AU. Preoperative chemotherapy treatment of breast cancer--a review (2007) Cancer 110:2394-407.

(25) Guarneri V, Frassoldati A, Ficarra G, Puglisi F, Andreetta C, Michelotti A, et al (2008) Phase II, randomized trial of preoperative epirubicin-paclitaxel +/- gefitinib with biomarker evaluation in operable breast cancer. Breast Cancer Res Treat 110:127-34.

(26) Dhesy-Thind B, Pritchard KI, Messersmith H, O'Malley F, Elavathil L, Trudeau M (2008) HER2/neu in systemic therapy for women with breast cancer: a systematic review. Breast Cancer Res Treat 109:209-29.

(27) Gennari A, Sormani MP, Pronzato P, Puntoni M, Colozza M, Pfeffer U, et al (2008) HER2 status and efficacy of adjuvant anthracyclines in early breast cancer: a pooled analysis of randomized trials. J Natl Cancer Inst 100:14-20.

(28) Buzdar AU, Ibrahim NK, Francis D, Booser DJ, Thomas ES, Theriault RL, et al (2005) Significantly higher pathologic complete remission rate after neoadjuvant therapy with trastuzumab, paclitaxel, and epirubicin chemotherapy: results of a randomized trial in 
human epidermal growth factor receptor 2-positive operable breast cancer. J Clin Oncol 23:3676-85.

Table 1. Pretreatment patient and tumor characteristics (ITT population) 


\begin{tabular}{|c|c|c|c|c|}
\hline \multirow[b]{2}{*}{ Characteristics } & \multicolumn{2}{|c|}{ Gefitinib (n=94) } & \multicolumn{2}{|c|}{ Placebo (n=86) } \\
\hline & Number (n) & Percent (\%) & Number (n) & Percent (\%) \\
\hline \multicolumn{5}{|l|}{ Age, years } \\
\hline Mean & 53 & & 53,1 & \\
\hline SD & 10.2 & & 10.5 & \\
\hline Range & 32,74 & & 31,74 & \\
\hline \multicolumn{5}{|l|}{ Histology } \\
\hline Ductal & 84 & 94.4 & 76 & 95 \\
\hline Lobular & 3 & 3.4 & 2 & 2.5 \\
\hline Other & 2 & 2.2 & 2 & 2.5 \\
\hline Missing & 5 & & 6 & \\
\hline \multicolumn{5}{|l|}{ Histologic grade } \\
\hline 1 & 1 & 1.1 & 1 & 1.2 \\
\hline II & 40 & 45.0 & 36 & 44.5 \\
\hline III & 48 & 53.9 & 44 & 54.3 \\
\hline Missing & 5 & & 5 & \\
\hline \multicolumn{5}{|l|}{ Tumor status } \\
\hline$<30 \mathrm{~mm}$ & 52 & 55.3 & 41 & 47.7 \\
\hline $31-50 \mathrm{~mm}$ & 36 & 38.3 & 37 & 43.0 \\
\hline$>51 \mathrm{~mm}$ & 6 & 6.4 & 8 & 9.3 \\
\hline \multicolumn{5}{|l|}{ HER2 } \\
\hline Normal & 56 & 59.6 & 46 & 53.4 \\
\hline Amplified & 22 & 23.4 & 32 & 37.2 \\
\hline Unsuitable & 16 & 17.0 & 8 & 9.3 \\
\hline
\end{tabular}

SD: Standard deviation.

ITT: Intention to treat.

Table 2. Major protocol deviations leading to exclusions from PP population

\begin{tabular}{lcc}
\hline & $\begin{array}{c}\text { Gefitinib }(\mathbf{n}=\mathbf{9 4}) \\
(\mathrm{n}, \text { percent })\end{array}$ & $\begin{array}{c}\text { Placebo }(\mathbf{n}=\mathbf{8 6}) \\
(\mathrm{n}, \text { percent })\end{array}$ \\
\hline $\begin{array}{l}\text { Number of patients with at least 1 major } \\
\text { deviation }\end{array}$ & $23(24.5)$ & $13(15.1)$ \\
Deviation & $6(6.4)$ & $2(2.3)$ \\
$\quad$ Tumor $<2 \mathrm{~cm}$ & $3(3.2)$ & $2(2.3)$ \\
$\quad$ Estrogen receptor positive & - & $1(1.2)$ \\
$\quad$ Distant metastases or bilateral breast cancer & $10(10.6)$ & $2(2.3)$ \\
$\quad$ Discontinuation because of safety reasons & $4(4.3)$ & $2(2.3)$ \\
$\quad \begin{array}{l}\text { Compliance } \\
\text { Less than } 10 \text { consecutive days of treatment } \\
\text { prior to surgery at } 12 \text { weeks }\end{array}$ & $17(18.1)$ & $6(7.0)$
\end{tabular}


Objective progression of disease during study period

Premature discontinuation for other reasons

No adequate tumor sample

Patients may have more than one major protocol deviation PP: Per protocol.

Table 3. The most frequent SAE's (ITT population)

\begin{tabular}{lcc}
\hline & $\begin{array}{c}\text { Gefitinib }(\mathbf{n}=94) \\
(\mathbf{n}, \text { percent })\end{array}$ & $\begin{array}{c}\text { Placebo }(\mathbf{n = 8 6}) \\
(\mathbf{n}, \text { percent })\end{array}$ \\
\hline Febrile Neutropenia & $17(18.1)$ & $8(9.3)$ \\
Fever & $3(3.2)$ & $4(4.7)$ \\
Leukopenia & $1(1.1)$ & $2(2.3)$ \\
Total patients with SAE & $25(26.6)$ & $14(16.3)$ \\
Total number of SAE's & $43(45.7)$ & $24(27.9)$ \\
\hline
\end{tabular}

SAE: Severe adverse event

ITT: Intention to treat.

Table 4. Baseline target tumor evaluation, PP

\begin{tabular}{cccc}
\hline & $\begin{array}{c}\text { Gefitinib } \\
(\mathrm{n}=71)\end{array}$ & $\begin{array}{c}\text { Placebo } \\
(\mathrm{n}=73)\end{array}$ & $\begin{array}{c}\text { Total } \\
(\mathrm{n}=144)\end{array}$ \\
\hline Longest diameter- physical (cm) & & & \\
$\mathrm{n}$ & 67 & 72 & 139 \\
Mean (SD) & $4.1(1.7)$ & $4.6(2.2)$ & $4.3(2.0)$ \\
Median & 4.0 & 4.0 & 4.0 \\
Range & 1,9 & 0,14 & 0,14 \\
Longest diameter - x-ray (cm) & & & \\
$\mathrm{n}$ & 62 & 59 & 121 \\
Mean (SD) & $3.4(1.7)$ & $3.6(1.5)$ & $3.5(1.6)$ \\
Median & 3.0 & 3.0 & 3.0 \\
Range & 1,12 & 1,8 & 1,12
\end{tabular}

Longest diameter- ultrasound (cm) 


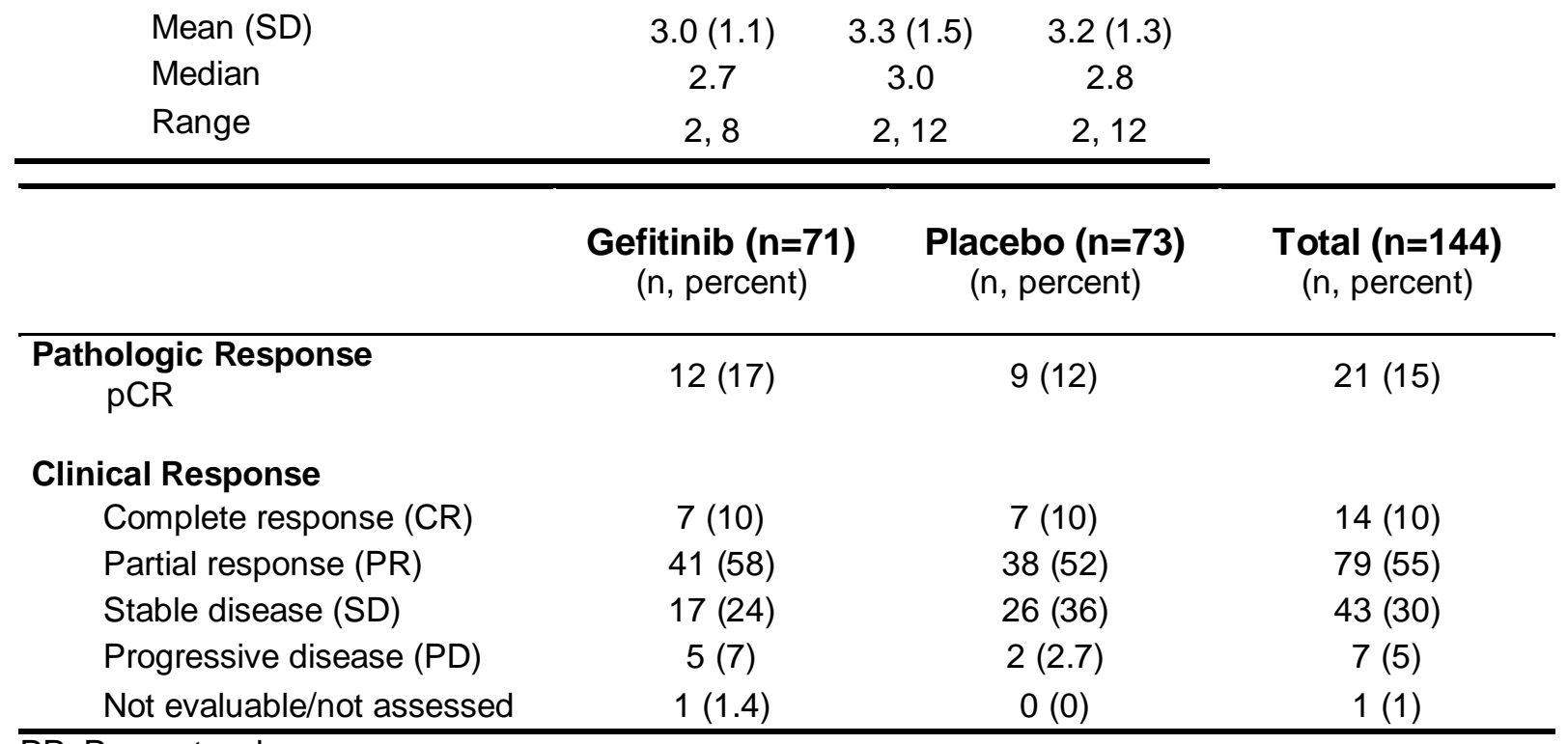

PP: Per protocol.

SD: Standard deviation

Table 5. Clinical and pathologic tumor response, PP

PP: Per protocol.

pCR: pathologic complete response.

Figure 1.

Safety analysis set

$\mathrm{n}=181$

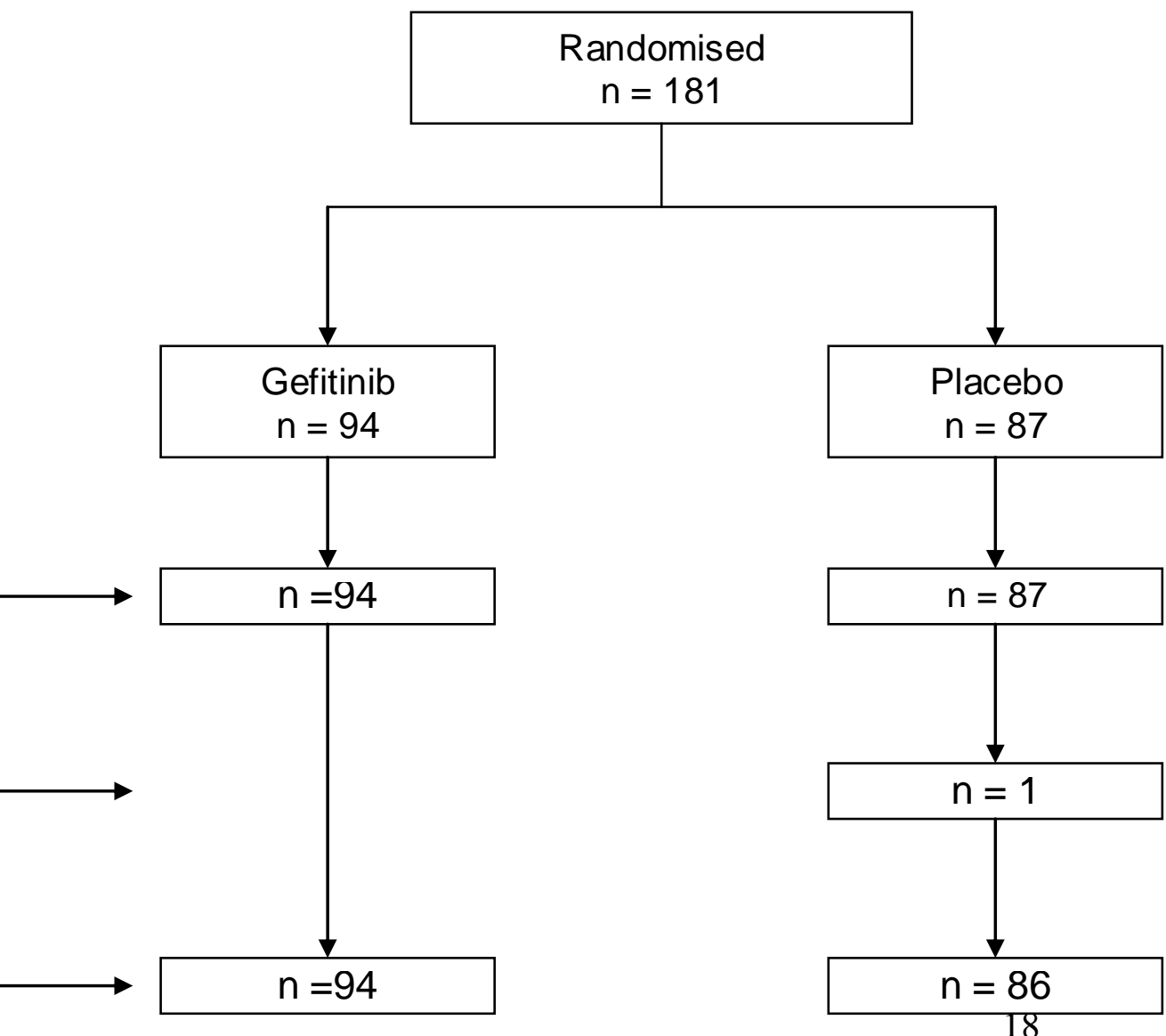

Reasons for exclusion:

No study drug $n=1$ 